\title{
Viscoelastic nature of Au nanoparticle-PDMS nanocomposite gels
}

\author{
RITU GUPTA ${ }^{1,4}$, HIMA K NAGAMANASA ${ }^{1}$, RAJESH GANAPATHY ${ }^{1,2}$ and \\ GIRIDHAR U KULKARNI ${ }^{3, *, \#}$ \\ ${ }^{1}$ Chemistry and Physics of Materials Unit, Jawaharlal Nehru Centre for Advanced Scientific Research, \\ Bangalore 560064, India \\ ${ }^{2}$ International Centre for Materials Science, Jawaharlal Nehru Centre for Advanced Scientific Research, \\ Bangalore 560064, India \\ ${ }^{3}$ Centre for Nano and Soft Matter Sciences, Jalahalli, Bangalore 560013, India \\ ${ }^{4}$ Present address: Birck Nanotechnology Centre, Purdue University, West Lafayette, IN 47907, USA
}

MS received 7 March 2015; accepted 18 May 2015

\begin{abstract}
A stable gel of Au nanoparticles in polydimethylsiloxane (PDMS) nanocomposite is prepared by employing the curing agent of PDMS elastomer as a reducing agent for the formation of Au nanoparticles by an in-situ process. The viscoelastic nature of these gels is very sensitive to the Au nanoparticle loading and the synthetic temperature conditions. Even a very low Au content of $0.09 \mathrm{wt} \%$ is sufficient enough to bring in the transition from sponge state to gel state at room temperature. Higher synthetic temperature also forms sponge formation. Infrared and ultraviolet-visible spectroscopy measurements have provided insight into PDMS crosslinking and nanoparticle formation, respectively. The optimization of the gel properties can have direct influence on the processability of Au nanoparticle-PDMS nanocomposite gels, with interesting implications in electronic, optical and microfluidic devices.
\end{abstract}

Keywords. Stability; viscoelastic; poly(dimethylsiloxane); Au nanoparticles; gels; crosslinking.

\section{Introduction}

Among the elastomeric gels, polydimethylsiloxane (PDMS) is well known for its structural and viscoelastic properties. ${ }^{1}$ In PDMS, the Si-O-Si chains forming the backbone exhibit low torsional barrier about the $\mathrm{Si}-\mathrm{O}$ bonds and as a result, the polymer exhibits a low glass transition temperature of $-125^{\circ} \mathrm{C}^{2}$ For similar reasons, it shows high flexibility and enhanced thermal stability. ${ }^{3}$ These unique properties have been utilized in a wide variety of applications from making of soft lithography stamps, encapsulation material to sealants, adhesives, stretchable devices, paints and even in cosmetics. ${ }^{4-9}$ It has been observed that PDMS in the form of a nanocomposite possesses unique and multifunctional properties as compared to its individual ingredients. ${ }^{10}$ The overall nature of PDMS can be significantly modulated by the addition of fillers. For example, silica and clay particles are added to PDMS to increase its mechanical stability. Similarly, conductive fillers such as carbon black, Ag flakes, graphene and carbon nanotubes (CNTs) are added to realize stretchable and compliant electrodes. ${ }^{11-13}$ A PDMS-CNT nanocomposite is shown to exhibit improved thermal properties. ${ }^{14,15}$

There are different ways of adding fillers to the polymer matrix, though the common method relies on physical mixing resulting in a solid suspension. ${ }^{16}$ While a uniform dispersion maximizing the interaction of the filler particles with the

\footnotetext{
*Author for correspondence (guk@cnsms.res.in)

\#On lien from JNCASR, Bangalore 560064, India.
}

PDMS matrix is highly desirable, any tendency towards aggregation due to particle-particle interaction can hinder the performance of the nanocomposite. ${ }^{17} \mathrm{~A}$ uniform dispersion of the nanomaterial is critical for the development of a PDMS nanocomposite for useful applications. ${ }^{18}$ The state of dispersion and influence of filler particles can be easily understood by studying the underlying rheological properties of the nanocomposite in gel form. ${ }^{19}$ The rheological properties of PDMS dispersed with CNTs, silica, clay, graphene have been examined in the past. Most of these studies involve only the PDMS elastomer without any crosslinker solidification. ${ }^{20-24}$ Often, the crosslinker is prevented or poisoned. ${ }^{25}$ In this study, we investigate the rheological properties of a nanocomposite, in-situ synthesized Au nanoparticles in PDMS matrix (AuPDMS), whose synthesis, essential characterization and some important properties were reported by us recently. ${ }^{26}$ During the synthesis, the curing agent in addition to serving as PDMS crosslinker acts as a reducing and stabilizing agent for $\mathrm{Au}$ nanoparticles (scheme 1), and thus the nanoparticles get embedded in PDMS. The nanocomposite prepared at ambient temperature was in the form of a gel, while at elevated synthetic temperatures $\left(>56^{\circ} \mathrm{C}\right)$ a sponge-like nanocomposite resulted.

Here in this study, we have systematically varied the synthetic temperature as well as the Au content and have investigated their influence on the viscoelastic properties of AuPDMS nanocomposites. The nanocomposites were also characterized by ultraviolet (UV)-vis and infrared (IR) spectroscopy to relate polymer crosslinking and nanoparticle formation with the viscoelastic behaviour. 

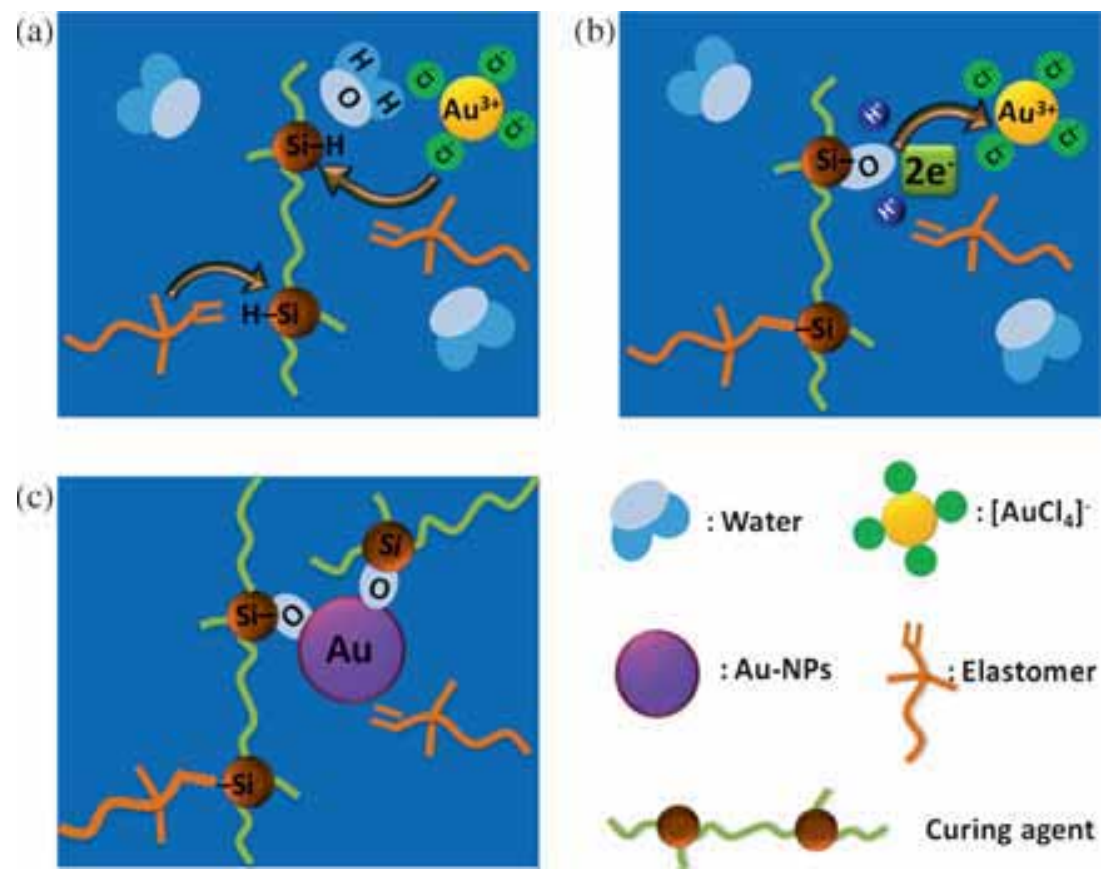

Scheme 1. Schematic of possible mechanism of Au nanoparticle formation in PDMS. (a) The elastomer units compete with aqueous Au precursor for $\mathrm{H}$-terminated $\mathrm{Si}$ sites present in curing agent. (b) Water molecule oxidizes the H-terminated Si sites present in the curing agent (top site) and in the process gives out electrons to the $\mathrm{Au}^{3+}$ ion. Such electrons coming from neighbouring sites (not shown) reduce the ion. (c) Nucleation of a Au nanoparticle at the $\mathrm{Si}-\mathrm{O}$ linkage. Some $\mathrm{Si}-\mathrm{H}$ sites (bottom) are utilized in direct crosslinking reaction.

\section{Experimental}

In all, seven AuPDMS nanocomposite gels were prepared for this study by following the procedure published previously. ${ }^{26}$ Briefly, in each case, an uncured PDMS mixture was prepared by mixing thoroughly the elastomer and the curing agent in a $10: 1 \mathrm{v} / \mathrm{v}$. The mixture weighing $2 \mathrm{~g}$ was taken in a glass vial containing $10 \mathrm{ml}$ of aqueous $\mathrm{KAuCl}_{4}$ solution of fixed concentration $(0.2,0.5,1$ and $2 \mathrm{mM})$ and stirred at room temperature $\left(26^{\circ} \mathrm{C}\right)$ while carrying out the synthesis for $2 \mathrm{~h}$ to form gel. The same procedure was repeated for a fixed aq. $\mathrm{KAuCl}_{4}$ solution of $1 \mathrm{mM}$ solution and varying the synthetic temperature $\left(36,46\right.$ and $\left.56^{\circ} \mathrm{C}\right)$. Importantly, the unreacted $\mathrm{KAuCl}_{4}$ was decanted out after each reaction and UV-vis measurement was done before and after reaction. The Au loading was calculated by estimating the $\mathrm{KAuCl}_{4}$ consumed using a calibration curve, which scales linearly with the $\mathrm{KAuCl}_{4}$ concentration (supplementary figure S1). The samples were washed with ethanol and kept in desiccator for $2 \mathrm{~h}$ to remove trapped air bubbles prior to rheological measurements. The ethanol washing is crucial for the stabilization of gels as seen in supplementary figure S2. A controlled stress rheometer (MCR 301-WESP) with a cone-plate geometry (diameter $25 \mathrm{~mm}$ and a cone angle of $2^{\circ}$ ) was used for the rheology measurements as shown in supplementary figure S3. All measurements were performed at room temperature and the humidity was maintained by enclosing it with an ordinary sponge wetted with water. The oscillatory strain amplitude sweep measurements were performed at a frequency of $10 \mathrm{rad} \mathrm{s}^{-1}$ with strain varying from 0.01 to $1000 \%$. The Fourier transform infrared spectroscopy (FT-IR) spectra were recorded using a Bruker IFS66-V/S spectrometer. The samples were prepared by mixing a small quantity of gel in $\mathrm{KBr}$ pellet. The UV-vis spectra were recorded directly from the films of AuPDMS sandwiched between two glass slides.

\section{Results and discussion}

The AuPDMS nanocomposites were prepared with different Au loadings (0.03-0.38 wt $\%$ designated as gel 1-4, see below) following the method published previously. ${ }^{26} \mathrm{The} \mathrm{Au}$ nanoparticle loading in nanocomposite was calculated from the consumption of $\mathrm{KAuCl}_{4}$ in PDMS as shown in supplementary figure $\mathrm{S} 4$ and expressed in wt $\%$. Briefly, the PDMS mixture (elastomer and curing agent in 10:1 ratio) was stirred with aq. $\mathrm{KAuCl}_{4}$ solution of varying concentrations $(0.1,0.5$, 1 and $2 \mathrm{mM}$ ) and at different temperatures $(26,36,46$ and $56^{\circ} \mathrm{C}$ ). The nanocomposites thus prepared exhibited the characteristic pinkish-purple colour (figure 1a), corresponding to fine dispersion of $\mathrm{Au}$ nanoparticles. For low Au content of $0.03 \mathrm{wt} \%$ (gel-1), the composite was obtained in the form of a viscoelastic solid and viscoelastic liquid at $0.09 \mathrm{wt} \%$ (gel-2). 
(a)

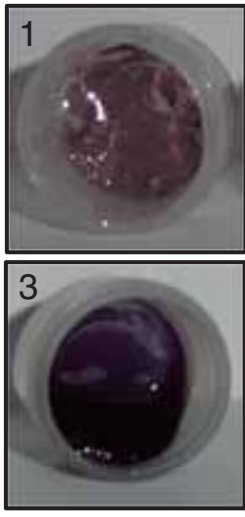

(c)

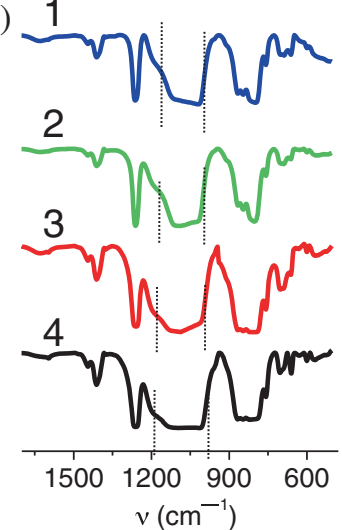

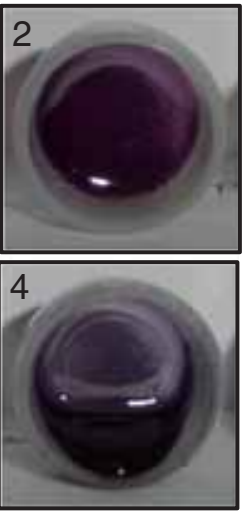

(b)

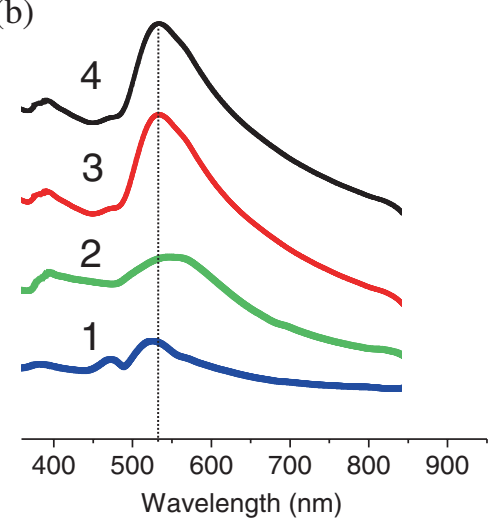

(d)

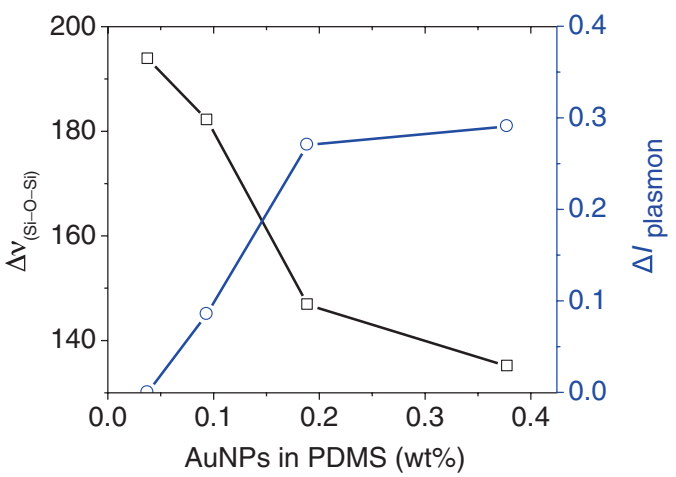

Figure 1. (a) Optical photographs and (b) UV-vis absorption spectra of AuPDMS nanocomposites prepared with different ratios of Au content and PDMS, (c) FT-IR spectra of the nanocomposites. The vertical lines mark the FWHM of Si-O-Si spectral feature. (d) Relative changes in the absorption intensity (right) and $\mathrm{Si}-\mathrm{O}-\mathrm{Si}$ peak intensities (left) for different Au content (wt \%) in PDMS. The numbers in $\mathbf{a}, \mathbf{b}$ and $\mathbf{c}$ indicate the nanoparticle loading in the gel, $0.03 \mathrm{wt} \%$ (1), $0.09 \mathrm{wt} \%$ (2), $0.19 \mathrm{wt} \%$ (3) and $0.38 \mathrm{wt} \%$ (4).

With higher Au loading of 0.19 and $0.38 \mathrm{wt} \%$ in gel-3 and gel-4, respectively, the obtained nanocomposites remained in the viscoelastic liquid state at room temperature (see figure 1a). This clearly represents a transition from a viscoelastic solid to a viscoelastic liquid with Au content as a tunable parameter. The UV-vis spectra (figure $1 \mathrm{~b}$ ) showed an absorption band at $530 \mathrm{~nm}$ corresponding to the surface plasmon of Au nanoparticles; it is broad and less intense for lower $\mathrm{Au}$ contents but gets well defined as the Au content increased in the nanocomposite (see figure $1 b$ ).

There is significant asymmetry at lower Au loadings probably due to polydispersity of nanoparticles. Electron microscopy examination requires disruption of the PDMS matrix for probing, and for this reason, imaging proved difficult. Nonetheless, at higher Au loadings (0.38 wt \%), the nature of particle dispersion could be examined in scanning electron microscopy (SEM; see supplementary figure S5). The nanoparticles were seen finely dispersed with an average size of $\sim 20 \mathrm{~nm}$. The degree of crosslinking for AuPDMS nanocomposite was examined by FT-IR spectroscopy. For spectral assignments, the literature values were used. ${ }^{27}$ The spectra exhibited a broad $\mathrm{Si}-\mathrm{O}-\mathrm{Si}$ asymmetric stretching in the range 1000-1130 $\mathrm{cm}^{-1}$. The $\mathrm{Si}-\mathrm{O}-\mathrm{Si}$ band gets broad and intense as the Au loading increases in PDMS gel as seen in figure 1c. The band at $1263 \mathrm{~cm}^{-1}$ due to $\mathrm{Si}-\mathrm{CH}_{3}$ (stretch) is expected to be unaffected and can thus be used for internal normalization. When the reduction of aq. $\mathrm{KAuCl}_{4}$ takes place in the PDMS matrix, the $\mathrm{Si}-\mathrm{H}$ sites present in the elastomeric chains get oxidized and convert to $\mathrm{Si}-\mathrm{O}-\mathrm{Si}$ linkage. ${ }^{28-30}$

Interestingly, there is an increase in the spread of the $\mathrm{Si}-$ $\mathrm{O}-\mathrm{Si}$ band on Au loading, which could probably be due to the changes in the structure of $\mathrm{Si}-\mathrm{O}$ main chain due to variety of distortions, branching and crosslinking. ${ }^{31}$ This clearly indicates that Au reduction to form nanoparticles in PDMS has a direct influence on its crosslinking property. The relation between the Au plasmon band intensity and the degree of crosslinking in PDMS was examined to understand the synergy between the nanoparticle formation and the crosslinking process (figure 1d). The plasmon peak intensity is seen to increase due to the higher density of nanoparticles and decreased crosslinking.

The PDMS curing time gets greatly accelerated on increasing the temperature. ${ }^{32}$ The enhanced crosslinking is marked by decreasing intensities of $\mathrm{Si}-\mathrm{H}$ and $\mathrm{Si}$-vinyl stretching 


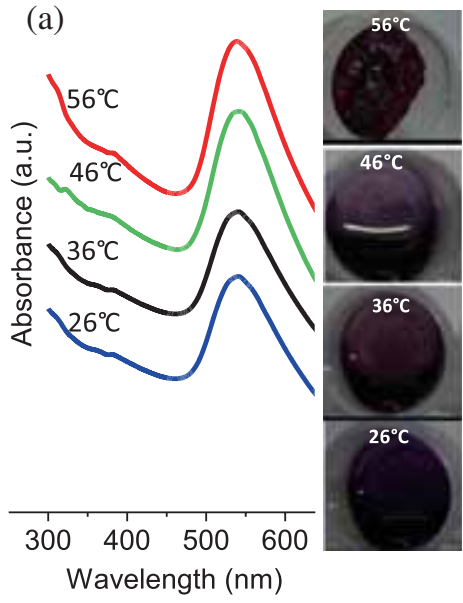

(b)
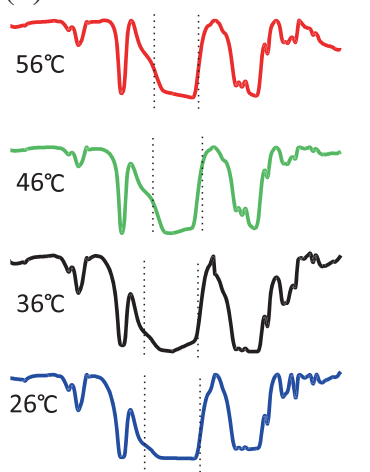

$1500 \quad 1200 \quad 900 \quad 600$ $v\left(\mathrm{~cm}^{-1}\right)$

(c)

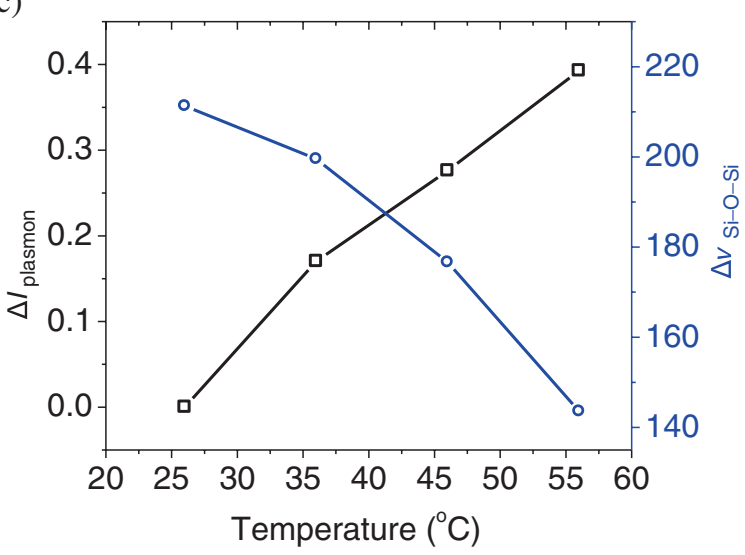

Figure 2. (a) UV-vis spectra of AuPDMS gels prepared at different temperatures; the photographs of the gels are shown alongside. (b) The corresponding IR spectra, (c) a double $y$-axes plot showing variations in the $530 \mathrm{~nm}$ plasmon peak intensity and the width of the $\mathrm{Si}-\mathrm{O}-\mathrm{Si}$ band with the synthetic temperature. The vertical lines in $\mathbf{b}$ mark the width of the $\mathrm{Si}-\mathrm{O}-\mathrm{Si}$ spectral feature.

occurring at 2159 and $1597 \mathrm{~cm}^{-1}$, respectively. ${ }^{30}$ There is also an equivalent effect on the formation of nanoparticles due to increased temperature. Thus, the influence of temperature on the nanoparticle formation and the curing of PDMS were further investigated (figure 2). The gels were prepared at different temperatures $\left(26,36,46\right.$ and $\left.56^{\circ} \mathrm{C}\right)$ for a fixed precursor concentration of $1 \mathrm{mM}$ (Au content $=0.19 \mathrm{wt} \%$ ). The UV-vis absorption spectra showed intense plasmon peak in all the cases, with only a small gain in the intensity (figure 2a).

Although Au content is fixed, the rate of nanoparticle formation differ for different temperatures. At higher preparation temperatures, the density of particles becomes higher along with increase in crosslinking of the polymer. However, the width of the plasmon absorption band is nearly constant indicating not much variation in the particle size distribution. This observation implies that the different degrees of polymer crosslinking and the different rates of nanoparticle formation are responsible for the transition of the physical state of the nanocomposite from liquid-like to solid form. As seen in FT-IR spectra, the $\mathrm{Si}-\mathrm{O}-\mathrm{Si}$ band is narrowed with higher crosslinking (figure $2 b$ ). A correlation similar to that in figure $1 \mathrm{c}$ could be obtained between the crosslinking process and the plasmon peak intensity for varying synthetic temperature. Given the difficulty associated with microscopy imaging in PDMS matrix, a study of the viscoelastic properties is worthwhile for understanding the nanoparticle dispersion and/or aggregation. ${ }^{33}$

In the case of AuPDMS nanocomposite, the Au nanoparticles hinder the curing process and its drastic influence can be quantitatively seen in viscoelastic measurements. The storage modulus $\left(\mathrm{G}^{\prime}\right)$ is related to the elastic properties, whereas the loss modulus $\left(\mathrm{G}^{\prime \prime}\right)$ describes the viscous behaviour of the material. For an uncured native PDMS, the $\mathrm{G}^{\prime \prime}$ value is usually high compared to $\mathrm{G}^{\prime}$, which is negligibly small and vice a versa for cured PDMS. ${ }^{34}$ As discussed above, there are, in all, three factors that can influence the viscoelastic properties namely, the nanoparticle density, size and distribution, and the degree of crosslinking of PDMS polymer. The linear viscoelastic behaviour of gels is expected to depend on all the above factors. ${ }^{35}$

The strength of the nanocomposite was characterized by carrying out amplitude sweep measurements with the strain amplitude varying from 0.01 to $500 \%$ at an angular frequency of $10 \mathrm{rad} \mathrm{s}^{-1}$. Figure $3 \mathrm{a}$ shows the variation of $\mathrm{G}^{\prime \prime}$ (loss modulus) and $\mathrm{G}^{\prime}$ (storage modulus) for plain PDMS gel. The viscoelastic response of plain PDMS is highly unstable due to the rapid crosslinking. Interestingly, the viscoelastic response becomes stable with the loading of Au nanoparticles as shown in figure $3 \mathrm{~b}$. The value of $\mathrm{G}^{\prime}$ is $\sim 105 \mathrm{~Pa}$ for $\mathrm{Au}$ content of $0.03 \mathrm{wt} \%$, whereas it decreases to $\sim 4 \mathrm{~Pa}$ at 0.19 wt $\%$ and remains almost constant up to $0.38 \mathrm{wt} \%$. For all the different Au loadings, the response is linear for a strain range of $0.01-50 \%$ with an overall decrease in its value with increasing Au loading. With increasing strain beyond $\sim 50 \%$, $\mathrm{G}^{\prime}$ exhibits a deviation from the linear response and becomes nonlinear, corresponding to the critical strain (figure $3 b$ ). The strain dependence of the dynamic viscoelastic properties in polymer nanocomposites is well known and often referred to as the Payne effect. For the least Au nanoparticle loading of $0.03 \mathrm{wt} \%$, we observe that at the critical strain, the decrease in $\mathrm{G}^{\prime}$ is also accompanied with a maximum in $\mathrm{G}^{\prime \prime}$, indicating the existence of Payne effect in these systems. ${ }^{34}$ Unlike what is routinely observed for polymer nanocomposites where $G^{\prime}$ and Payne effect increase with filler loading, surprisingly, here we find that with increase in Au nanoparticle loading (filler in our case), $\mathrm{G}^{\prime}$ and $\mathrm{G}^{\prime \prime}$ decrease and correspondingly the Payne effect is also reduced. ${ }^{33}$ In addition, the absence of nonlinear effects up to $100 \%$ strain for all the nanoparticle loadings suggest that $\mathrm{Au}$ nanoparticles are finely dispersed in the PDMS matrix. ${ }^{34}$ This is also consistent with what has been observed in scanning transmission electron microscopy and SEM images (see supplementary figure S5). The wide range observed for the linear regime in these nanocomposite systems is remarkable. The higher value of loss modulus in figure $3 \mathrm{c}$ indicates a liquid-type behaviour. Further, figure $3 \mathrm{~d}$ shows a clear transition from solid to liquid type behaviour at a critical nanoparticle loading of $0.09 \mathrm{wt} \%$. 
(a)

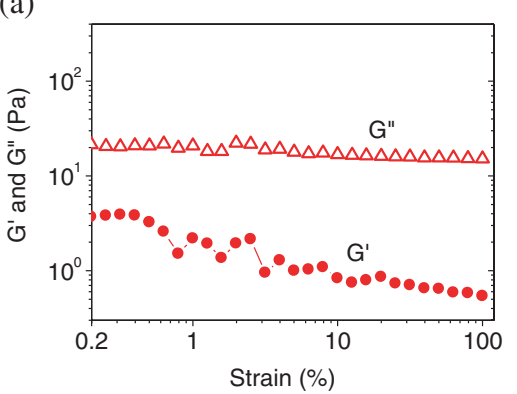

(c)

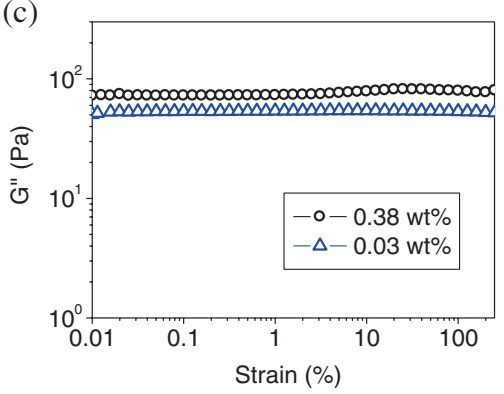

(b)

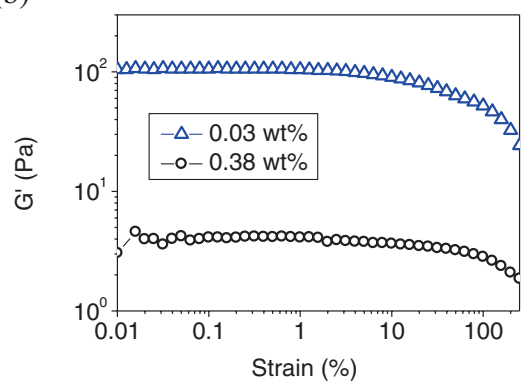

(d)

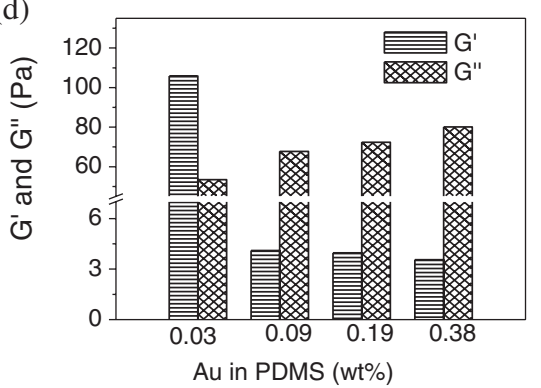

Figure 3. The strain amplitude sweep for (a) PDMS, (b) storage modulus $\left(\mathrm{G}^{\prime}\right)$ and (c) loss modulus $\left(\mathrm{G}^{\prime \prime}\right)$ for Au PDMS composite gels with different Au content at constant frequency of $1 \mathrm{rad} \mathrm{s}^{-1}$ for strain varying from 0.01 to $1000 \%$. (d) The average storage and loss moduli of different gels prepared with different Au content.

The value of $\mathrm{G}^{\prime \prime}$ increases only marginally with higher loading of Au nanoparticles, whereas $\mathrm{G}^{\prime}$ for $0.09 \mathrm{wt} \%$ is nearly 25 times lowered as compared with $0.03 \mathrm{wt} \%$. This is in accordance with the FT-IR data, which points to lesser crosslinking with higher loading of AuNPs (figure 3). The liquid-type behaviour due to lower crosslinking affirms the fact that some part of curing agent is utilized in the reduction of $\mathrm{Au}$ precursor to AuNPs.

Thus far, our results show that curing agent plays a crucial role not only in crosslinking PDMS but also in the reduction of $\mathrm{Au}$ nanoparticles. However, it is well known that the degree of crosslinking in plain PDMS depends on temperature. ${ }^{32}$ Hence, to probe the effect of temperature on the nature of AuPDMS nanocomposites, rheological measurements were performed on gels prepared at different temperatures for a fixed loading of $\mathrm{Au}$ nanoparticles. Figure 4 shows $\mathrm{G}^{\prime}$ (solid symbols) and $\mathrm{G}^{\prime \prime}$ (hollow symbols) for a nanoparticle loading of $0.19 \mathrm{wt} \%$ prepared at $26,36,46$ and $56^{\circ} \mathrm{C}$. For AuPDMS prepared at lower temperatures such as $26^{\circ} \mathrm{C}$, the value of storage modulus is quite low, being less than $5 \mathrm{~Pa}$ (figure 4a). With increase in temperature, both $\mathrm{G}^{\prime}$ and $\mathrm{G}^{\prime \prime}$ show an increase (figure $4 \mathrm{~b}-\mathrm{d}$ ). The values of both $\mathrm{G}^{\prime}$ and $\mathrm{G}^{\prime \prime}$ remain almost linear up to $100 \%$ of applied strain, suggesting the absence of nanoparticle-nanoparticle interactions at room temperature as well as at higher temperatures (due to fine dispersion of nanoparticles) as also confirmed by transmission electron microscopy analysis. Interestingly, the value of $\mathrm{G}^{\prime}$ increases by nearly 160 times due to the formation of more viscoelastic solid-like gel of the nanocomposite at $56^{\circ} \mathrm{C}$, which can be seen in the histogram plotted in figure 4e. The variation in the damping factor (given by $\left.\tan \delta=\mathrm{G}^{\prime \prime} / \mathrm{G}^{\prime}\right)$ can be used to characterize the viscoelasticity of the nanocomposite. A higher value of $\tan \delta$ implies that the material is predominantly liquid-like. As shown in figure $4 \mathrm{f}$, there is clearly a trade-off between the storage modulus and damping. The elevated temperatures increase the solid-like viscoelastic behaviour of the nanocomposites and decrease the liquid-like behaviour at a given oscillatory frequency; this is due to the rapid rate of reduction of the $\mathrm{Au}$ precursor accompanied by the faster curing of PDMS.

\section{Conclusions}

In conclusion, we have shown that by a simple in situ reduction of Au nanoparticle in PDMS, a well-dispersed nanocomposite may be synthesized. Even under high strain, the particle dispersion in these nanocomposites remains stable. Only strains beyond $100 \%$ make them structurally collapse. The reduction of $\mathrm{Au}$ nanoparticle in PDMS at room temperature is an interesting process. It takes place inside the PDMS matrix in situ without any external reducing or capping agent. The Au nanoparticle loading helps to stabilize the gel. As the Auwt\% in PDMS increases (0.38 wt\%), the nanocomposite assumes a flowing gel state as opposed to a solid film at lower loadings $(0.03 \mathrm{wt} \%)$. We find that the strain at which softening sets in, shifts to a higher value with increase in Au load. Furthermore, with increase in nanoparticle loading the values of $\mathrm{G}^{\prime}$ and $\mathrm{G}^{\prime \prime}$ as well as the Payne effect decrease. Depending on the preparation temperature, the crosslinker may get 

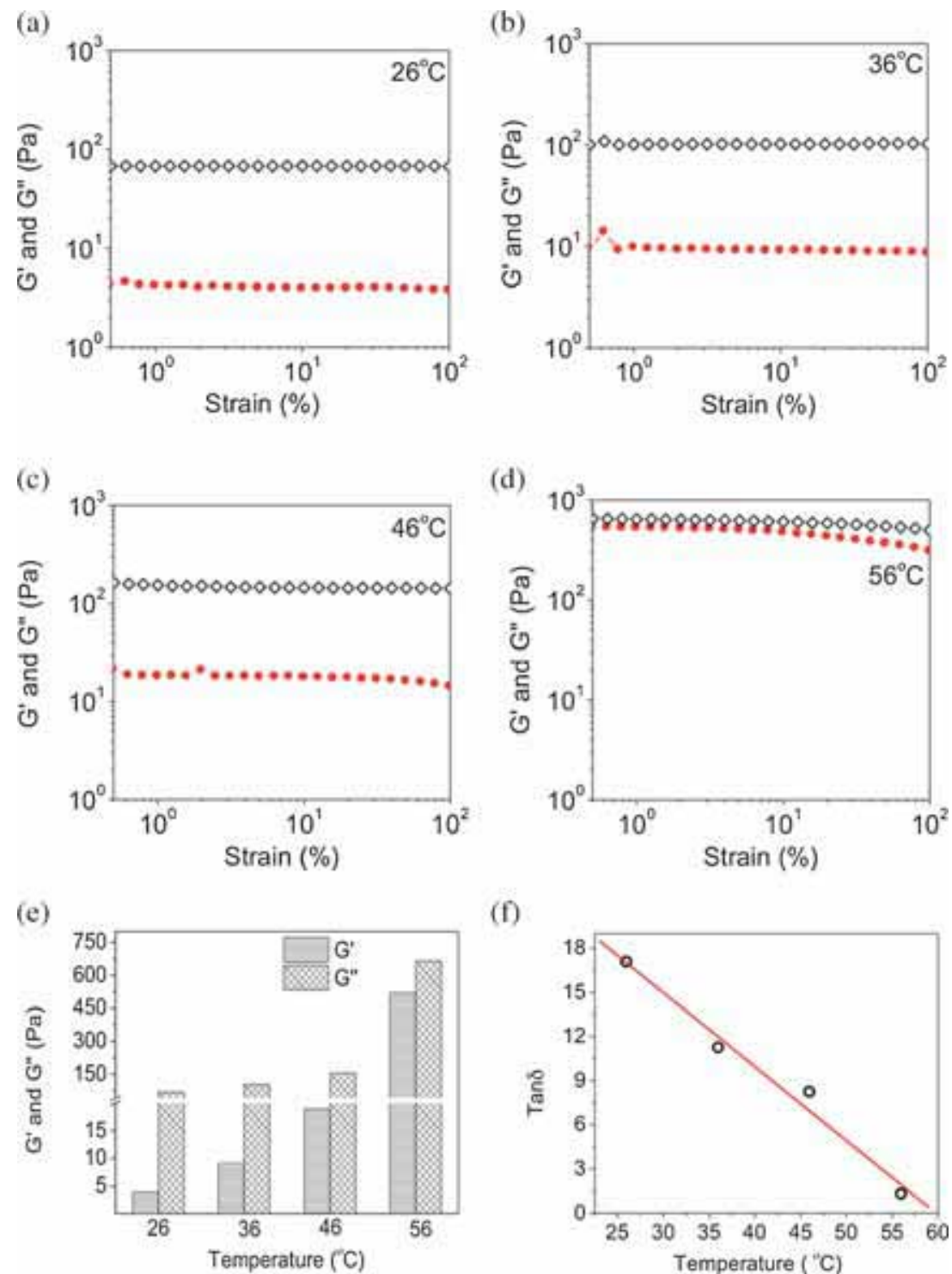

(f)

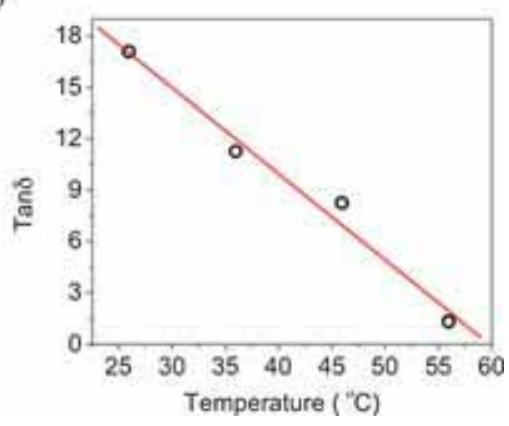

Figure 4. The strain amplitude sweep at constant frequency of $10 \mathrm{rad} \mathrm{s}^{-1}$ for strain varying from 0.01 to $100 \%$ for AuPDMS nanocomposite (Au content of $0.19 \mathrm{wt} \%$ prepared at (a) 26 (b) 36 (c) 46 and (d) $56^{\circ} \mathrm{C}$ ). Solid and hollow symbols correspond to $\mathrm{G}^{\prime}$ and $\mathrm{G}^{\prime \prime}$, respectively. (e) A histogram of storage and loss moduli and (f) the damping factor, $\tan \delta$, for the nanocomposites prepared at different temperatures.

preferentially engaged in the polymerization process or in the nanoparticle reduction (see scheme 1). The insights obtained in this study may be useful in understanding the viscoelastic behaviour of nanocomposites in general and even while designing new nanocomposites.

\section{Acknowledgements}

We thank Professor CNR Rao for his encouragement. Support from the Department of Science and Technology, Government of India, is gratefully acknowledged. RG thanks ICMS, JNCASR for financial support. Thanks to K Veeresh and Swati (CPMU, JNCASR) for their assistance in gel preparation and B Vanitha for manuscript formatting.

\section{Electronic Supplementary Material}

Supplementary Material pertaining to this article is available on the Bulletin of Materials Science website (www.ias.ac.in/ matersci).

\section{References}

1. Takahashi H, Ishimuro Y and Watanabe H 2006 Nihon Reoroji Gakk 34135

2. Mark J E 2004 Acc. Chem. Res. 37946

3. Rajan G, Sur G, Mark J, Schaefer D and Beaucage G $2003 \mathrm{~J}$. Polym. Sci. Pol. Phys. 411897

4. Qin D, Xia Y and Whitesides G M 2010 Nat. Protoc. 5491 
5. Lacour S P, Wagner S, Huang Z and Suo Z 2003 Appl. Phys. Lett. 822404

6. Adrega T and Lacour S P 2010 J. Micromech. Microeng. 20 055025

7. Buyl F D 2001 Int. J. Adhes. Adhes. 21411

8. Rosen M R 2005 Delivery system handbook for personal care and cosmetic products: technology, applications and formulations (Norwich, NY: William Andrew Publishing) ISBN: 978-0-8155-1504-3

9. Kumar S K and Krishnamoorti R 2010 Annu. Rev. Chem. Biomol. Eng. 137

10. Niu X Z, Peng S L, Liu L Y, Wen W J and Sheng P 2007 Adv. Mater. 192682

11. Cong H and Pan T 2008 Adv. Funct. Mater. 181912

12. Kujawski M, Pearse J D and Smela E 2010 Carbon 48 2409

13. Zhang Y, Sheehan C J, Zhai J, Zou G, Luo H, Xiong J, Zhu Y T and Jia Q X 2010 Adv. Mater. 223027

14. Hong J, Lee J, Hong C K and Shim S E 2010 Curr. Appl. Phys. 10359

15. Liu C H and Fan S S 2005 Appl. Phys. Lett. 86123106

16. Mackay M E 2006 Science 3111740

17. Kayatin M J and Davis V A 2009 Macromolecules 426624

18. Moreira L, Fulchiron R, Seytre G, Dubois P and Cassagnau P 2010 Macromolecules 431467

19. Anderson B J and Zukoski C F 2010 Langmuir 268709

20. Huang Y Y, Ahir S V and Terentjev E M 2006 Phys. Rev. B 73 125422
21. Bokobza L and Diop A L 2010 Express Polym. Lett. 4355

22. Austin J R and Kontopoulou M 2006 Polym. Eng. Sci. 46 1491

23. Guimont A, Beyou E, Martin G, Sonntag P and Cassagnau P 2011 Macromolecules 443893

24. Marceau S, Dubois P, Fulchiron R and Cassagnau P 2011 Macromolecules 443893

25. Takahashi H, Ishimuro Y and Watanabe H 2007 Nihon Reoroji Gakk 35191

26. Scott A, Gupta R and Kulkarni G U 2010 Macromol. Chem. Phys. 2111640

27. Muñoz P, Patricia M A and Vargas M D 2001 J. Appl. Polym. Sci. 823460

28. Zhang Q, Xu J J, Liu Y and Chen H Y 2008 Lab. Chip 8352

29. Zhang Q, Xu J J, Liua Y and Chen H Y 2008 Lab. Chip 8352

30. Goyal A, Kumar A, Patra P K, Mahendra S, Tabatabaei S, Alvarez Pedro J J, John G and Ajayan P M 2009 Rapid Commun. 301116

31. Rau K R, Singh R and Goldberg E 2002 Mat. Res. Innovat. 5 162

32. Cai D and Neyer A 2010 Microfluid Nanofluid 9855

33. Bhattacharya S, Srivastava A and Pal A 2006 Angew. Chem. Int. Ed. 452934

34. Thomas S and Stephen R 2009 Rubber nanocomposites: preparation, properties and applications (Wiley) ISBN: 978-0-47082345-3

35. Walberer J A and McHugh A J 2001 J. Rheol. 45187 